\title{
Growth in height compared with advancement in skeletal maturity in patients treated with human growth hormone
}

\author{
R D G MILNER, M A PREECE, AND J M TANNER
}

\author{
Department of Paediatrics, University of Sheffield, and Department of Growth and Development, \\ Institute of Child Health, London
}

SUMMARY Height growth and skeletal maturation were compared in 201 patients treated for between 1 and 15 years with growth hormone (GH) supplied by the Medical Research Council. 107 patients had isolated GH-deficiency, 30 had panhypopituitarism, and 64 craniopharyngiomata. The mean rate of skeletal maturation did not differ between the first year and the total period of treatment, averaging 1 'year'/year in the patients with isolated GH-deficiency or panhypopituitarism, and 0.6 'years'/year in those with craniopharyngioma. No association was observed between the rate of skeletal maturation and the bone age or the bone age deficit (chronological minus bone age) at the start of treatment. Mean height standard deviation score for bone age was negative in all three diagnostic groups at the start of treatment, but became less negative as treatment progressed in patients with isolated GH-deficiency or craniopharyngioma. In patients with panhypopituitarism there was no significant change in height standard deviation score for bone age as a result of treatment. The findings do not support the suggestion that treatment with $\mathrm{GH}(\mathrm{UK})$ causes ultimate stunting due to greater osseous maturation than growth in height.

The therapeutic response to treatment with human growth hormone (GH(UK)) provided first by the Medical Research Council and now by the Department of Health and Social Security has been reported in some detail. ${ }^{1-2}$ The impression that this therapeutic regimen is generally satisfactory was recently challenged ${ }^{3}$ and it was alleged that treatment with $\mathrm{GH}(\mathrm{UK})$ causes disproportionate osseous maturation for height gain, with ultimate stunting. It is suggested that these effects are due to contaminating pituitary peptides, in particular gonadotropins, which are responsible for supposedly premature stimulation of gonadal function. Earlier accounts of treatment with $\mathrm{GH}(\mathrm{UK})^{2}$ and other therapeutic GH preparations ${ }^{4-5}$ did not report inappropriate skeletal maturation as a result of treatment, but in view of the serious implications of this recent communication we have studied in detail

Department of Paediatrics, University of Sheffield

R D G MILNER, professor of paediatrics

Department of Growth and Development, Institute of Child

Health

M A PREECE, senior lecturer in growth and development

J M TANNER, professor of child health and growth the records of 201 children treated with $\mathrm{GH}(\mathrm{UK})$, particularly their growth in height and advancement in skeletal maturity.

\section{Patients and methods}

The 201 patients comprised all those who have been treated for at least one year with GH(UK) since 1959 , for whom serial records of height growth and bone age were available. Many of them attended the growth clinic at The Hospital for Sick Children, London, and a few attended other growth centres in the UK. The patients were divided into three diagnostic groups: 107 had isolated GH-deficiency, 30 (referred to as panhypopituitary) had a deficiency of more than one anterior pituitary hormone, and 64 suffered from a craniopharyngioma. The treatment regimens varied within and between patients and included all the protocols described in the report of the MRC Working Party. ${ }^{1}$ In the patients with panhypopituitarism 18 received thyroxine, 11 glucocorticoids, 3 vasopressin, and 1 testosterone in addition to GH. Among the patients with craniopharyngioma 56 received thyroxine, 44 gluco- 
corticoids, 30 vasopressin, 15 testosterone, 7 oestrogens or progesterone (or both), 4 gonadotrophins, and 11 anticonvulsants. In the analyses of growth no distinction was made between the sexes or between those receiving $\mathrm{GH}(\mathrm{UK})$ alone or in combination with other hormones.

Stature was measured as described previously ${ }^{2}$ and osseous maturation was estimated as the TW2 radius, ulnar, and short bone age. ${ }^{6}$ Bone age velocity (bone age 'years'/chronological year) was calculated over the first year of treatment and also for the total period of treatment. In some patients GH treatment was not continuous, and in these bone age velocity was calculated using the number of years of GH treatment and not the total time as the denominator. For example, if a bone age advanced 4 'years' in 6 chronological years during which $\mathrm{GH}(\mathrm{UK})$ treatment had been given for 5 years, a result of 0.8 would be recorded for 5 years of treatment.

Whenever bone age was estimated, the height standard deviation (SD) score ${ }^{2}$ was recorded both for chronological age and bone age. The height SD score for bone age and change in height SD score for bone age was analysed in each group of patients by the number of years that continuous treatment with $\mathrm{GH}$ had been given. (a)
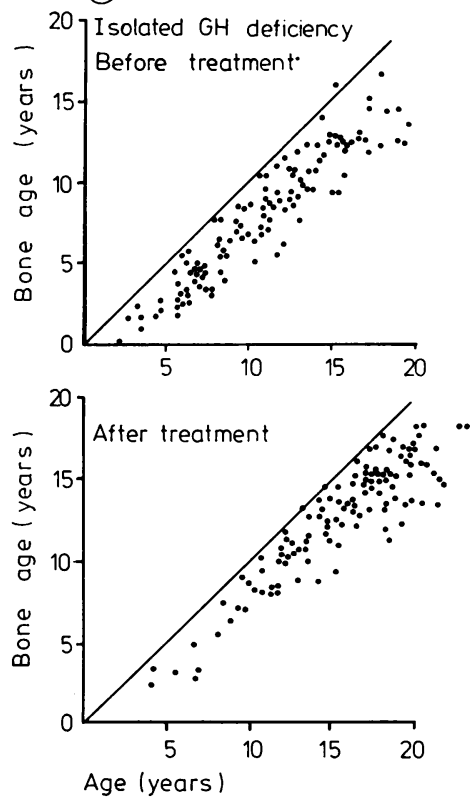

(b)
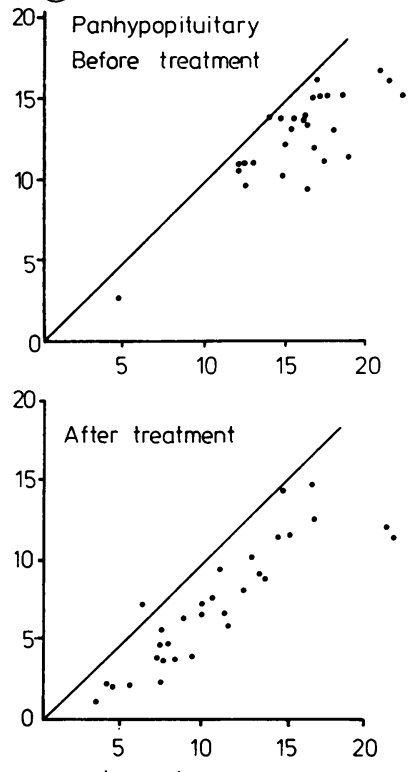

Age (years)
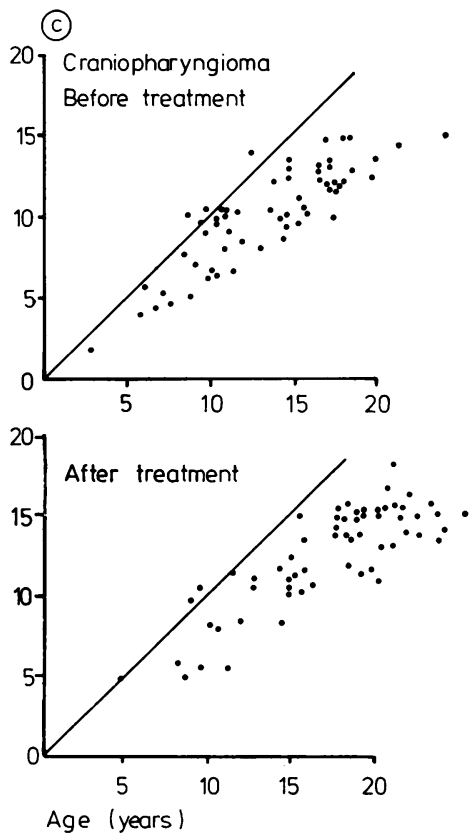

Fig. 1 Bone age plotted against chronological age before and after GH treatment in patients with (a) isolated GH deficiency, (b) panhypopituitarism, and (c) craniopharyngioma.

Table 1 Mean ( \pm SEM) bone age velocity ('years'/year) of patients with isolated GH deficiency, panhypopituitarism, or craniopharyngioma related to the duration of treatment with $G H$

\begin{tabular}{|c|c|c|c|}
\hline $\begin{array}{l}\text { Duration of treatment } \\
\text { with GH (years) }\end{array}$ & Isolated GH deficiency & Panhypopituitarism & Craniopharyngioma \\
\hline $\begin{array}{l}1 \\
2 \\
3 \\
4 \\
5 \\
6 \\
7 \\
8 \\
9 \\
>10\end{array}$ & $\begin{array}{l}0.79 \pm 0.16(n=14) \\
0.95 \pm 0.16(n=11) \\
0.94 \pm 0.06(n=11) \\
1.09 \pm 0.07(n=26) \\
1.00 \pm 0.08(n=13) \\
1.10 \pm 0.06(n=16) \\
0.89 \pm 0.15(n=6) \\
0.84 \pm 0.09(n=3) \\
1.12 \quad(n=1) \\
1.00 \pm 0.07(n=6)\end{array}$ & $\begin{array}{l}0.61 \pm 0.28(n=2) \\
1.19 \pm 1.02(n=2) \\
1.15 \quad(n=1) \\
0.83 \pm 0.22(n=5) \\
1.13 \pm 0.13(n=5) \\
0.81 \pm 0.86(n=3) \\
1.11 \pm 0.23(n=4) \\
0.97 \pm 0.16(n=5) \\
1.16 \pm 0.49(n=2) \\
0.66 \quad(n=1)\end{array}$ & $\begin{array}{c}0.35 \pm 0.12(n=12) \\
0.65 \pm 0.17(n=11) \\
0.52 \pm 0 \cdot 19(n=10) \\
0.60 \pm 0.09(n=13) \\
0.65 \pm 0.09(n=6) \\
0.70 \pm 0.07(n=5) \\
0.70 \quad(n=1) \\
0.72 \pm 0.20(n=3) \\
\square\end{array}$ \\
\hline Total & $0.99 \pm 0.09(n=107)$ & $0.97 \pm 0.07(n=30)$ & $0.57 \pm 0.05(n=61)$ \\
\hline
\end{tabular}




\section{Results}

Bone age. The bone age of the patients in each diagnostic group is shown plotted against chronological age at the beginning (Fig. 1, upper panels) and end of treatment (Fig. 1, lower panels). The

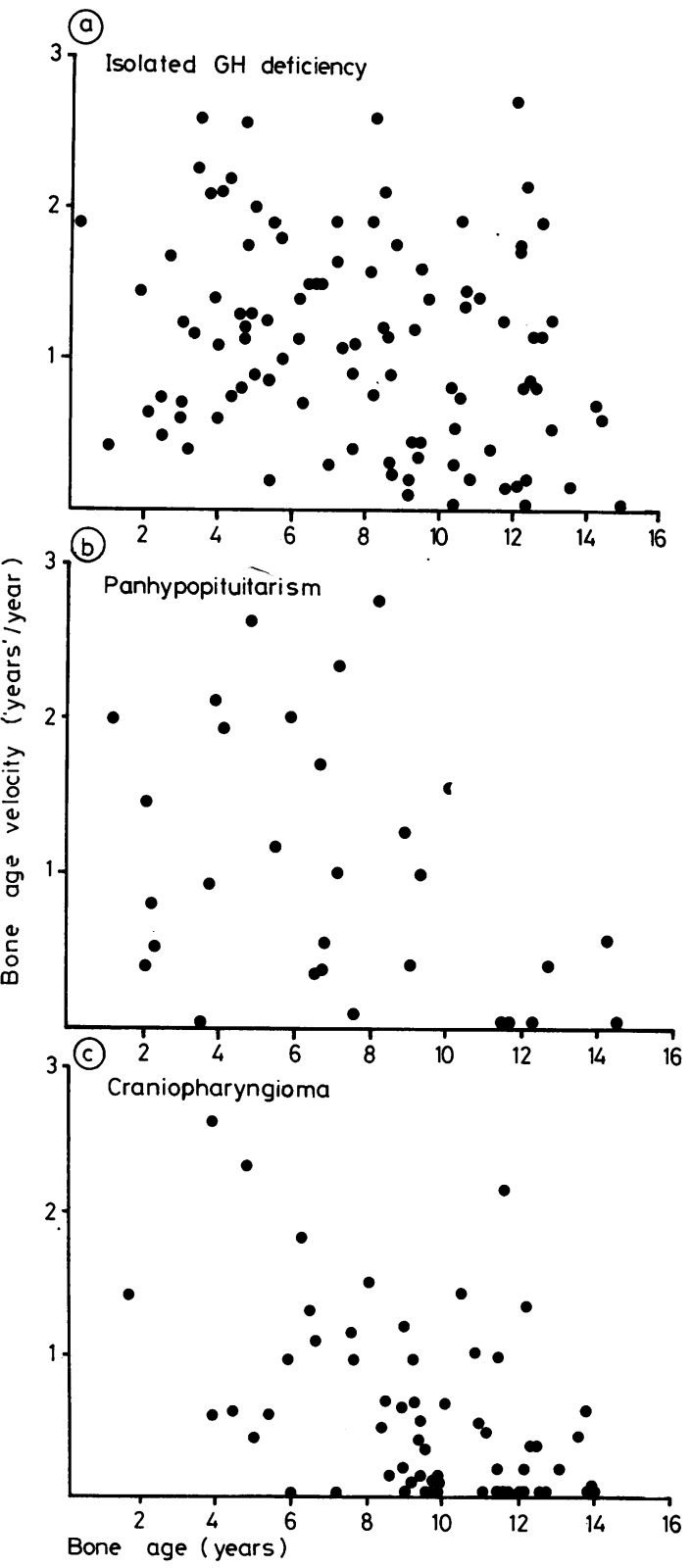

Fig. 2 Bone age velocity in the first year of treatment plotted against bone age at the start of treatment in patients with (a) isolated $G H$ deficiency, (b) panhypopituitarism, or (c) craniopharyngioma. failure of individual patients to fall above the line of identity for bone and chronological age at the end of treatment is evidence that inappropriate bone age maturation did not occur as a result of treatment with GH.

The rate of bone age advance was analysed according to the number of years of treatment to see if there was any trend in bone age velocity due to the duration of therapy (Table 1). Bone age velocity was not related to the length of treatment in any diagnostic group. The overall mean velocity of patients with isolated GH deficiency or panhypopituitarism was similar-0.99 and 0.97 'years'/ year-each of which was significantly greater than the mean velocity in craniopharyngioma-0.57 'years'/year.

Fig. 2 shows bone age velocity during the first year of treatment plotted against bone age at the beginning of treatment in the three diagnostic groups. There is no association except that in the craniopharyngioma groups there was a tendency towards low velocity in those patients with bone ages of 10 or more at the start of treatment. The mean overall bone age velocity in each diagnostic group during the first year of treatment (Table 2) was similar to the mean velocity calculated over the total period of treatment with $\mathrm{GH}$, being $1 \cdot 11$ and 1.00 'years'/year for the isolated $\mathrm{GH}$ and panhypopituitary groups, and 0.56 'years'/year in craniopharyngioma.

Bone age velocity in the first year of treatment of

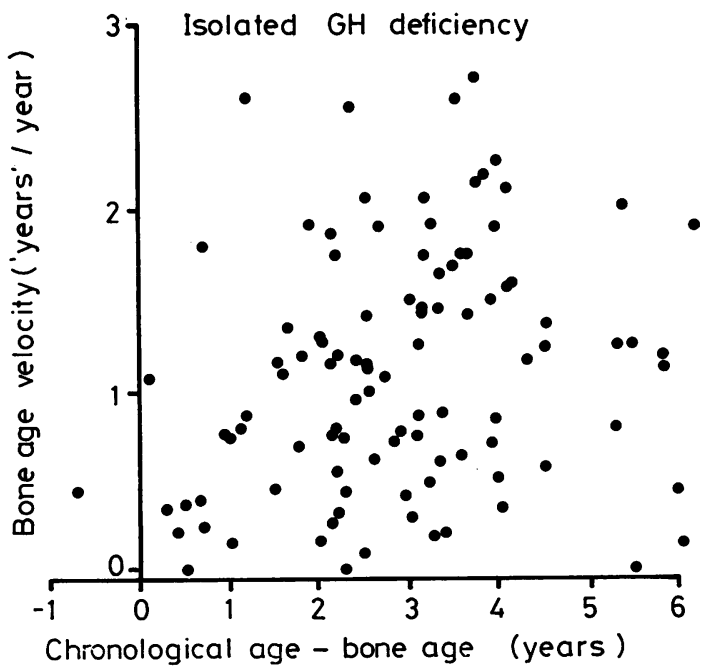

Fig. 3 Bone age velocity in the first year of treatment plotted against the difference between chronological age and bone age at the start of treatment in patients with isolated GH deficiency. 
Table 2 Mean ( \pm SEM) bone age velocity of patients with GH deficiency, panhypopituitarism, or craniopharyngioma in the first year of treatment

\begin{tabular}{|c|c|c|c|}
\hline $\begin{array}{l}\text { Bone age at } \\
\text { start of treatment }\end{array}$ & Isolated $G H$ deficiency & Panhypopituitarism & Craniopharyngioma \\
\hline $\begin{array}{l}0+ \\
1+ \\
2+ \\
3+ \\
4+ \\
5+ \\
6+ \\
7+ \\
8+ \\
9+ \\
10+ \\
11+ \\
12+ \\
13+ \\
14+ \\
15+\end{array}$ & $\begin{array}{ll}1.92 & (\mathrm{n}=1) \\
0.79 \quad(\mathrm{n}=2) \\
0.83 \pm 0.24(\mathrm{n}=5) \\
1.48 \pm 0.29(\mathrm{n}=8) \\
1.35 \pm 0.18(\mathrm{n}=13) \\
1.29 \pm 0.27(\mathrm{n}=7) \\
1.15 \pm 0.19(\mathrm{n}=7) \\
1.15 \pm 0.22(\mathrm{n}=6) \\
1.32 \pm 0.24(\mathrm{n}=11) \\
0.71 \pm 0.22(\mathrm{n}=8) \\
0.82 \pm 0.22(\mathrm{n}=9) \\
0.80 \pm 0.36(\mathrm{n}=4) \\
1.18 \pm 0.24(\mathrm{n}=13) \\
0.64 \quad(\mathrm{n}=3) \\
0.42 \quad(\mathrm{n}=3) \\
0.44 \quad(\mathrm{n}=1)\end{array}$ & 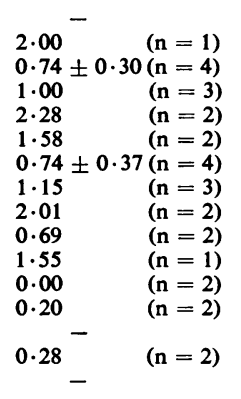 & 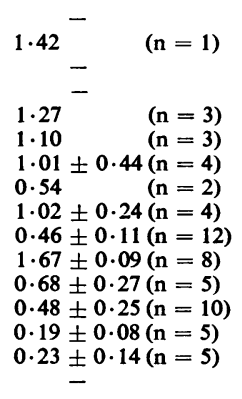 \\
\hline Total & $1 \cdot 11 \pm 0.07(n=101)$ & $1 \cdot 00 \pm 0 \cdot 16(n=30)$ & $0.56 \pm 0.08(n=62)$ \\
\hline
\end{tabular}

Table 3 Cumulative mean ( $\pm S E M$ ) height standard score for bone age in patients with isolated GH deficiency, panhypopituitarism, or craniopharyngioma related to duration of treatment

\begin{tabular}{|c|c|c|c|}
\hline $\begin{array}{l}\text { Continuous treatment } \\
\text { with } G H \text { (years) }\end{array}$ & Isolated $G H$ deficiency & Panhypopituitarism & Craniopharyngioma \\
\hline $\begin{array}{l}0 \\
1 \\
2 \\
3 \\
4 \\
5 \\
6 \\
7\end{array}$ & $\begin{array}{l}-1.77 \pm 0.16(\mathrm{n}=104) \\
-1.47 \pm 0.16(\mathrm{n}=104) \\
-1.29 \pm 0.20(\mathrm{n}=65) \\
-1.34 \pm 0.17(\mathrm{n}=54) \\
-1.39 \pm 0.19(\mathrm{n}=47) \\
-1.40 \pm 0.19(\mathrm{n}=24) \\
-1.22 \pm 0.28(\mathrm{n}=15) \\
-1.12 \pm 0.36(\mathrm{n}=5)\end{array}$ & $\begin{array}{l}-1.75 \pm 0.46(n=28) \\
-1.31 \pm 0.45(n=28) \\
-1.94 \pm 0.41(n=18) \\
-1.81 \pm 0.42(n=17) \\
-1.40 \pm 0.36(n=16) \\
-1.34 \pm 0.44(n=12) \\
-1.89 \pm 0.38(n=8) \\
-1.94 \pm 0.58(n=5)\end{array}$ & $\begin{array}{l}-1.28 \pm 0.15(\mathrm{n}=64) \\
-0.82 \pm 0.16(\mathrm{n}=64) \\
-0.16 \pm 0.21(\mathrm{n}=32) \\
-0.15 \pm 0.27(\mathrm{n}=23) \\
-0.28 \pm 0.32(\mathrm{n}=14) \\
-0.34 \pm 0.40(\mathrm{n}=7) \\
-0.03 \quad(\mathrm{n}=3) \\
-0.5 \quad(\mathrm{n}=1)\end{array}$ \\
\hline
\end{tabular}

Table 4 Final height of 59 patients treated with $G H(U K)$

\begin{tabular}{lccc}
\hline & Isolated GH deficiency & Panhypopituitarism & Craniopharyngioma \\
\hline Above 1st centile & & & \\
$\quad$ Boys & $16(\mathrm{n}=19)$ & $7(\mathrm{n}=9)$ & $12(\mathrm{n}=13)$ \\
Girls & $5(\mathrm{n}=7)$ & $5(\mathrm{n}=5)$ & $6(\mathrm{n}=6)$ \\
All & $21(\mathrm{n}=26)$ & $12(\mathrm{n}=14)$ & $18(\mathrm{n}=19)$ \\
Within target & $5(\mathrm{n}=19)$ & $5(\mathrm{n}=9)$ & $5(\mathrm{n}=13)$ \\
Boys & $5(\mathrm{n}=7)$ & $3(\mathrm{n}=5)$ & $3(\mathrm{n}=6)$ \\
Girls & $10(\mathrm{n}=26)$ & $8(\mathrm{n}=14)$ & $8(\mathrm{n}=19)$ \\
All & & &
\end{tabular}

patients with isolated GH-deficiency was analysed to see if there was an association with degree of retardation of osseous development-that is chronological age minus bone age (Fig. 3). There is no significant relation between these variables $(n=103$, $r=0 \cdot 22, P>0 \cdot 05$ ).

Height. Height gained while on treatment with GH was analysed with reference to bone age so that the hypothesis that $\mathrm{GH}$ causes disproportionate osseous maturation for height gain could be tested. The mean height SD score for bone age in the three diagnostic groups is shown in relation to the number of years of continuous treatment with GH (Table 3). In the largest group, isolated GH deficiency, the score became progressively less negative as the duration of treatment increased, indicating that the children gained more in height than in osseous maturation as a result of GH therapy. Patients with craniopharyngioma showed a pronounced 'catch up' in height for bone age in the first 5 years of treatment. In the smallest group, those with panhypopituitarism, 


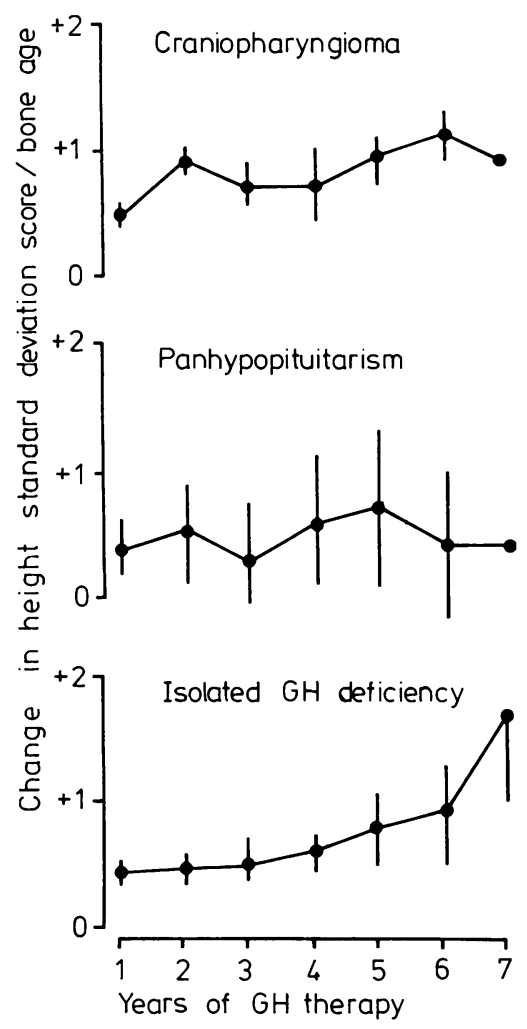

Fig. 4 Mean ( $\pm S E M)$ change in height standard deviation score for bone age in patients with isolated growth hormone deficiency, panhypopituitarism, and craniopharyngioma plotted against the number of years of continuous treatment with $G H$.

there was no trend in height SD score and the patients gained height appropriately for their bone age throughout the 7 years of treatment. The change in height SD score for bone age in the three diagnostic groups is shown (Fig. 4). In Fig. 5 the individual plots of 15 patients with isolated $\mathrm{GH}$ deficiency treated for 6 years are presented to illustrate the considerable variation that may be observed between patients.

Growth had ceased in 59 of the patients. In 51 cases the final height was above the 1st centile. Approximately half the patients achieved a height within the target defined by their parents' height ${ }^{\text {? }}$ (Table 4).

\section{Discussion}

$\mathrm{n}$ this study there was no patient selection; the ubjects are all those in the UK for whom suitable ecords of height and bone age were available. The

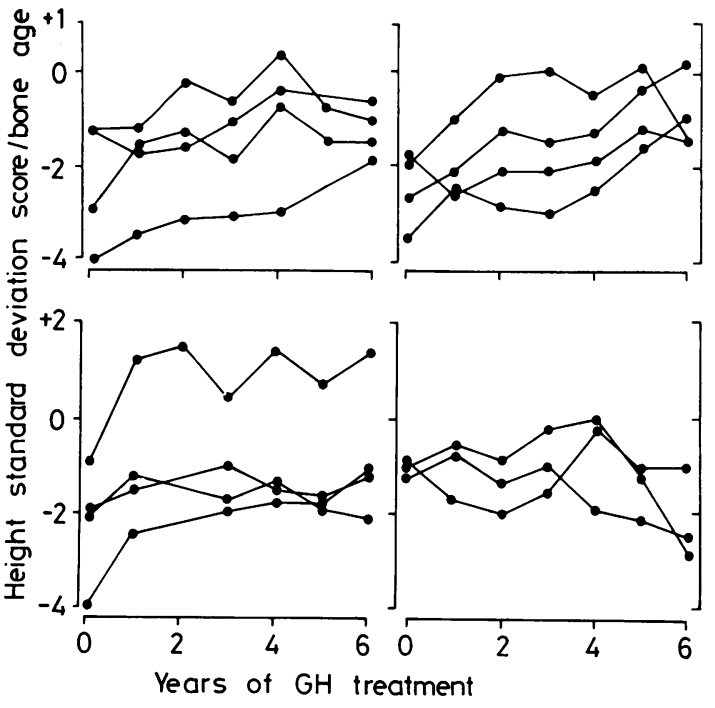

Fig. 5 Height standard deviation score for bone age in 15 patients with isolated $\mathrm{GH}$ deficiency who received GH treatment for 6 years plotted individually against duration of treatment.

patients were divided into three groups because the majority of those with panhypopituitarism or craniopharyngioma received treatment with other hormones in addition to GH. Although both groups had multiple hormonal therapy, it seemed appropriate to consider them separately; patients with panhypopituitarism were thought to have had a life-long deficiency of pituitary hormones whereas those with craniopharyngioma were thought to have grown normally until the development of the neoplastic condition.

All measurements of bone age were made by the same method and most of them $(>90 \%)$ by one person. This, coupled with the large numbers studied, made it possible to examine patterns of skeletal maturation with confidence. The bone age velocity calculated over the total period of treatment varied between 0 and 3 'years'/year, but the distribution between patients within a treatment group was skewed positively. The average bone age velocity of a group was similar when calculated at the end of the first year or throughout treatment. No explanation can be offered for the difference in mean bone age velocity observed between isolated GH-deficiency and panhypopituitarism on the one hand, and craniopharyngioma on the other. The mean bone age velocity of the first two groups demonstrates that treatment with $\mathrm{GH}(\mathrm{UK})$ alone, or in combination with other hormones when 
required, results in a normal rate of osseous development. Two factors may contribute to the significantly lower bone age velocity of patients with craniopharyngioma. Firstly, almost all of them had been unwell at some stage, often seriously; secondly many were taking corticosteroids. Either factor would tend to delay bone age substantially.

Growth in height in relation to skeletal development can be analysed by the calculation of height SD score for bone age. The demonstration that height SD score for bone age improved as treatment with GH continued in the patients with isolated GH deficiency, clearly refutes the idea that GH(UK) causes inappropriate osseous maturation for height gained. The figure showing the response of individual patients treated for 6 years demonstrates the danger of drawing conclusions from a small sample. In 2 patients there was a fall, in 3 no change, and in 10 a rise in height SD score for bone age. The results in craniopharyngioma were similar to those in isolated GH deficiency but the numbers were fewer. In panhypopituitarism no significant change in height SD score was observed, indicating parallel and appropriate response to treatment in both height and skeletal maturation.

We thank Miss S E Ibbotson for assistance with the analyses. Most of the height measurements and bone age assessments were made by $\mathrm{Mr} \mathrm{R} \mathrm{H}$ Whitehouse and Dr N Cameron, and Dr B Carter developed the computer programs which enabled efficient retrieval of the source data.

\section{References}

1 Milner R D G, Russell-Fraser T, Brook C G D, et al. Experience with human growth hormone in Great Britain: the report of the MRC Working Party. Clin Endocrinol $(O x f) 1979 ; 11$ : 15-38.

2 Tanner J M, Whitehouse R H, Hughes P C R, Vince F P. Effect of human growth hormone treatment for 1 to 7 years on growth of 100 children with growth hormone deficiency, low birthweight, inherited smallness, Turner's syndrome, and other complaints. Arch Dis Child 1971; 46: 745-82.

3 Hamilton W. What can be expected from growth hormone therapy? (abstract). Arch Dis Child 1979; 54: 971-2.

4 Prader A, Zachmann M, Poley J R, Illig R, Széky J. Long-term treatment with human growth hormone (Raben) in small doses. Evaluation of 18 hypopituitary patients. Helv Paediatr Acta 1967; 22 : 423-40.

5 Soyka L F, Bode H H, Crawford J D, Flynn F J, Jr. Effectiveness of long-term human growth hormone therapy for short stature in children with growth hormone deficiency. J Clin Endocrinol Metab 1970; 30: 1-14.

- Tanner J M, Whitehouse R H, Marshall W A, Healy M J R, Goldstein H. Assessment of skeletal maturity and prediction of adult height. London: Academic Press, 1975.

7 Tanner J M. Foetus into man. Physical growth from conception to maturity. London: Open Books, 1978: 194.

Correspondence to Professor R D G Milner, Department of Paediatrics, Children's Hospital, Sheffield S10 2TH.

Received 13 November 1979 